\title{
Breast clinic referrals: can mastalgia be managed in primary care?
}

\author{
A. K. Coskun · A. Harlak $\cdot$ O. Mentes
}

Received: 11 February 2014/ Accepted: 28 April 2014/Published online: 14 May 2014

(C) Royal Academy of Medicine in Ireland 2014

Sir,

We read the recent article by Joyce et al. [1] titled "Breast clinic referrals: can mastalgia be managed in primary care?" published online in the Irish Journal of Medical Science (doi:10.1007/s11845-013-1066-z) with great interest. The authors evaluated symptomatic breast units' referrals and attendances, and they wanted to correlate referrals and attendances with diagnoses to identify a cohort of patients who may be suitable for management in a primary care setting. They concluded that because patients under 35 with isolated mastalgia have a very low risk for breast cancer, a primary care setting may be appropriate for the evaluation of these patients. When we read the article, a few questions came to mind. We feel that clarification regarding the following details would be useful.

First, we would like to know more about the components of the triple assessment used in the study. As is known, the components of a triple assessment are clinical examination, radiological assessment (mammography or ultrasound) and pathological assessment (cytology or biopsy). According to the Royal College of Radiologists guidelines, the initial radiological assessment for symptoms related to the breast is mammography for patients over the age of 35 and ultrasound for patients under 35 [2]. As a dense breast is more common in patients under 35, radiological imaging is not sensitive in picking up any suspicious lesions. We are curious about what kind of procedure the authors used for radiological assessment in

A. K. Coskun $(\bowtie) \cdot$ A. Harlak · O. Mentes

Department of Surgery, Gulhane School of Medicine,

Ankara, Turkey

e-mail: kagancoskun@gmail.com both groups: mammography or ultrasound? If they did not use the same procedure for both groups, then how was statistical analysis done for two groups of patients with different imaging modalities?

Second, in Table 2, the authors called one of the symptoms "mastalgia plus abscess". However, this situation could be called pain, and mastalgia could be defined as a pain that continues more than five days and affects daily life [3]. During the evaluation of an abscess, ultrasound is the first-line investigation due to its painless application and because it provides regular breast evaluation during the therapy [4]. We are curious about whether mammography was used as an imaging modality during the evaluation of patients with "mastalgia plus abscess"? Which procedure was used by the authors?

Finally, the authors highlighted very important points regarding time, cost and usage of the sources in the management of patients with mastalgia. Clarification of the points we mentioned above would make this article more understandable and valuable.

\section{Conflict of interest None.}

\section{References}

1. Joyce DP, Alamiri J, Lowery AJ et al (2014) Breast clinic referrals: can mastalgia be managed in primary care? Ir J Med Sci. doi:10.1007/s11845-013-1066-z (Epub ahead of print)

2. Board of the Faculty of Clinical Radiology (2003) Guidance on screening and symptomatic breast imaging, 2nd edn. Royal College of Radiologists, London

3. Millet AV, Dirbas FM (2002) Clinical management of breast pain: a review. Obstet Gynecol Surv 57:451-461

4. Trop I, Dugas A, David J et al (2011) Breast abscesses: evidencebased algorithms for diagnosis, management, and follow-up. Radiographics 31(6):1683-1699. doi:10.1148/rg.316115521 